\title{
der junge zahnarzt
}

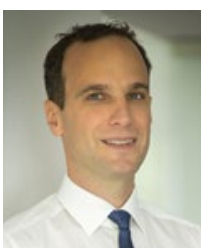

\section{Dr. Christian Honert}

Redaktionsbeirat

"der junge zahnarzt"

Unser Redaktionsbeirat

Dr. Norbert Grosse, Wiesbaden

Dr. Lisa Hierse, Magdeburg

Dr. Christian Honert, Asbach

Prof. Dr. Anahita Jablonski-Momeni, Marburg

Dr. Dr. Philipp Kauffmann, Göttingen

Dr. Christopher Köttgen, Mainz

Dr. Dr. Markus Tröltzsch, Ansbach

\section{Liebe Kolleginnen, liebe Kollegen,}

Wer will das nicht: Einfach entspannt die geplante Arbeit am Patienten, ob jung oder alt, erledigen. Doch was tun, wenn ständig innegehalten werden muss, weil der Patient den Kopf weg zieht, da er das Gefühl hat, zu ertrinken? Der Würgereiz lässt es mal wieder nicht zu, den $\mathrm{Ab}$ drucklöffel sauber zu platzieren? Stellen Sie sich dicke Kullertränen bei den kleinsten Patienten vor, die einem selber an die Substanz gehen. Oder schlicht, aber leider gar nicht so einfach: Die Angst vor uns Zahnärzten hat eine solche Größe erreicht, dass Schweißausbrüche und Herzrasen auf Maximum sind, lange bevor der Behandlungsstuhl erreicht ist?

Genau hier zeigt unser Topthema "Zahnbehandlung unter Hypnose“ eine geeignete Maßnahme, um die Zusammenarbeit zwischen Patient und Zahnarzt deutlich zu verbessern. Was bedeutet eigentlich Hypnose und wie wende ich sie an? Was gilt es zu beachten, und wo kann ich meine ersten Schritte in die
Hypnose-unterstützte Therapie erlernen? Dr. Albrecht Schmierer und Dr. Angela Freundorfer berichten über ihre Arbeit mit Hypnose und wie man einen Einstieg in dieses spannende Fachgebiet findet.

Muss es immer eine umfangreiche Augmentation bei ungünstigen Knochenverhältnissen sein, um das Implantat mit Standardlänge zu setzen, oder besteht stattdessen nicht die Möglichkeit, einfach ein kürzeres Implantat zu inserieren? Gerade der Patient kommt schnell ins Grübeln, wenn es um eine zusätzliche Operation geht. Das spannende Fortbildungsthema „Kurze Implantate vs. Augmentation" befasst sich mit der Frage, in welchen Situationen der Einsatz von kürzeren Implantaten eine Alternative darstellt und wie es mit der aktuellen Studienlage ausschaut.

Ich wünsche Ihnen viel Spaß mit unserer neuen Ausgabe und verbleibe mit herzlichen Grüßen

Ihr Christian Honert

SpringerZahnmedizin.de

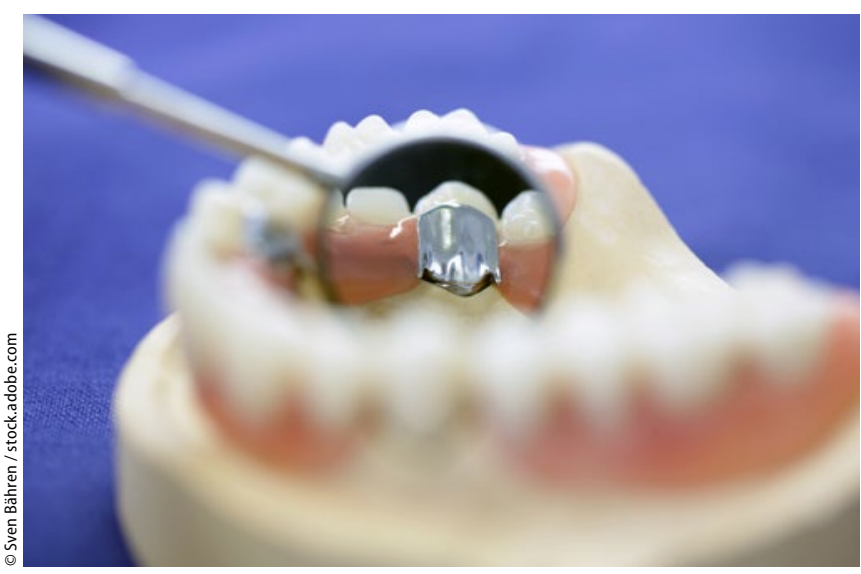

fortbildung

14 Kurze Implantate vs. Augmentation

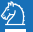

CME

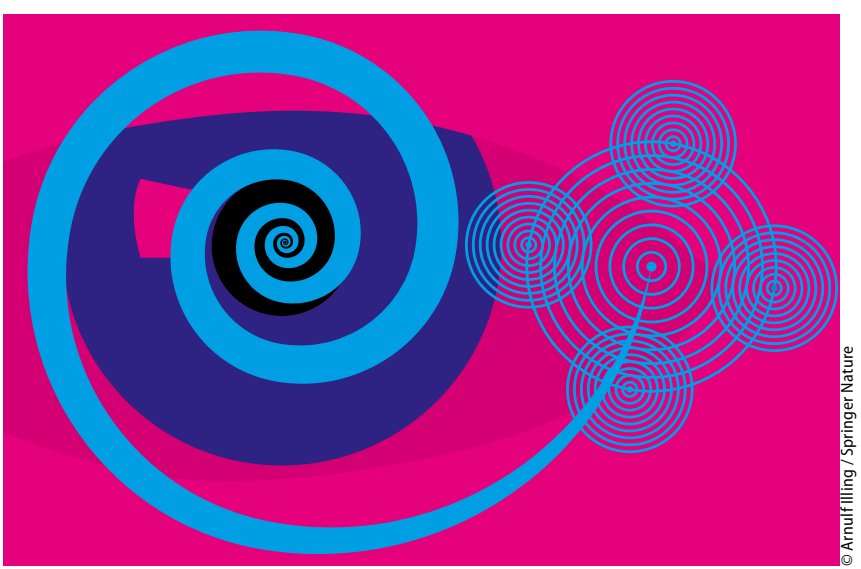

titelthema

26 Zahnbehandlung unter Hypnose eine Win-win-Situation für Patient und Zahnarzt

Hypnose kann Angstpatienten eine angenehme Behandlung ermöglichen. Zwei Kollegen berichten von ihren Erfahrungen.

Dr. Beate Fessler // München
Dr. Dr. Michael Dau, PD Dr. Dr. Peer W. Kämmerer, MA, FEBOMFS // Rostock 